African Journal of Biomedical Research, Vol. 7 (2004); 113 -118 ISSN 1119 - 5096 C Ibadan Biomedical Communications Group Available online at http://www.bioline.org.br/md

Full Length Research Article

\title{
THE EFFECT OF MOTHERS PAST DENTAL EXPERIENCE ON THE BEHAVIOUR OF SOME NIGERIAN CHILDREN DURING DENTAL TREATMENT
}

\author{
O. O. BANKOLE ${ }^{1 *}$, O. O. DENLOYE, G. A. ADERINOKUN \\ Department of Preventive Dentistry, Faculty of Dentistry, College of Medicine, University of \\ Ibadan. Ibadan, Nigeria.
}

\begin{abstract}
The objective of this study was to assess the effect of the mother's past dental experience on the behaviour of some Nigerian children during dental treatment. Two hundred and sixty children aged $3-15$ years participated in this study. They were treated at the three government dental establishments in Ibadan, a city in southwestern Nigeria, over a six-month period. The children's behaviour during different stages of treatment were determined by the Frankl's Behaviour Rating Scale. The outcome of the study revealed that the mother's past dental experiences were found to influence the children's behaviour at the initial steps of treatment. On entering the operatory, $92.5 \%$ of the children whose mothers had pleasant memories of their dental experiences reacted positively in comparison to $60 \%$ who had mothers with previous traumatic experiences $(p<0.05)$. During examination, $92.5 \%$ of children whose mothers enjoyed dental treatment in the past complied, while $68.0 \%$ who had mothers with past negative experiences were cooperative $(p<0.05)$. Behaviour of children at latter stages of treatment revealed a tendency towards improved behaviour where the mothers past dental experiences had been pleasurable. From this study, it has been established that enquiring into the mother's past dental experience, among other things, is important for successful child dental care. Even though it was significant only at the preliminary stages of treatment, it would appear that these stages are the most critical in gaining the childs confidence and getting him accustomed to the clinic environment. In circumstances where mother's past dental experience has been negative, the dentist will need to educate, counsel and allay the fears, which may have persisted in such parents for years. This will help reassure the parents as the mothers cooperation will be needed in order to provide the children with the best dental care. Where the mothers' unpleasant dental experiences had influenced the childs behaviour negatively, efforts should be geared towards instituting appropriate behaviour management skills in these children in order to bring about a higher level of compliance during dental visits.
\end{abstract}

Key Words: Dental, treatment, Experience, Mother, Past, Fear, Child.

\section{INTRODUCTION}

The subject of anxiety as related to dental treatment has been of interest for several decades. Dental treatment may result in a stressful situation and research has indicated that a considerable proportion of the population is scared about visiting the dentist. Studies carried out by Dionne et al, (1998) in the United States of America revealed that nearly $30 \%$ of respondents in their study affirmed that they were terrified about visiting the dentist. Semenova et al, (1999) reviewing literature on psychological research in dentistry, revealed that at least $25 \%$ of adults are afraid of visiting the dentist, with fear of pain being the most frequent reason. An increasing body of evidence support the view that negative attitudes towards dentistry have their genesis principally in childhood or adolescents (Lautch, 1971, Locker et al, 1999). Fear of dentists appears to be more common in children. Klingberg et al, (1994) reported that prevalence estimates of children who are afraid of visits to the dentist vary and can be

\footnotetext{
${ }^{1}$ Corresponding Author:

Email address: bumbank2002@yahoo.com; Tel: 2348033607853
} 
as high as $43 \%$ depending on the methods and populations surveyed.

The origin of dental fears are numerous and complex and according to Finn (1973), one of the ways by which a child can acquire dental fears is subjectively, based on information from others without the individual having experienced the situation himself. Hawley et al, (1974) reported that there was significant negative behaviour in children who had interacted with someone with an unpleasant dental experience. Similarly, frightening comments made by other children and adults have resulted in children reacting unfavourably at the dental clinic (Korf, 1977,). Wakiaga, (1996) stated that fears arising from information given by other dental patients were important reasons which kept some members of the populace from visiting the dentist. To further buttress this assertion, some patients who are fearful of dental treatment have been found to come from families who have had unpleasant dental experiences and especially where these fears are typically expressed. Al-Khodair et al,(1996) in a study of dental phobia among Saudis, reported that patients with dental fear had a greater family history of dental phobia. Research carried out by Locker et al, (1999) similarly revealed that a family history of dental anxiety was predictive of dental fear in children.

Even though all the members of the family are important in influencing the behaviour of the child, the mother appears to be the most influential family member. Observations by researchers have revealed that children with high dental anxiety had mothers who had previous negative dental experiences and were scared of dental treatment (Shaw, 1975, Klingberg et al, 1995, Arnrup et al, 2002).

Literature investigating the relationship of mothers past dental experience to the behaviour of their children in the dental setting in Nigeria appears to be rather scarce. There is certainly a need to increase the level of knowledge in this aspect of dentistry. It is hoped that this study will provide new information in that regard. This should facilitate better oral care delivery to Nigerian children.

\section{MATERIALS AND METHODS}

This study was conducted in Ibadan, a city located in southwestern Nigeria. The subjects consisted of children between the ages of 3-15 years, attending the three government dental clinics in the city. All the children seen and treated over a six-month period were included in the study. A team of dental surgeons and therapists who had earlier been informed according to a standard format carried out examination and treatment of the subjects.

In addition to demographic information, the mothers were asked to rate their own past dental experiences. The operators, using the Frankl's Behaviour Rating Scale (Frankl, et al 1962), made an assessment of the behaviour exhibited by each child during different phases of treatments. The four-point scale of Frankl, which has been a prototype for many studies abroad and in this environment, and has been found reliable(Winer;1980,Sote 1985). Inter-rater reliability was calculated from the percentage of agreements between the investigators and this was $92 \%$.

The criteria for scoring were as follows.

Rating 1 - Definitely Negative - Refusal of treatment, crying forcefully, fearful or any overt evidence of extreme negativism.

Rating 2 - Negative- Reluctant to accept treatment, some evidence of negative attitude but not pronounced.

Rating 3 - Positive- Acceptance of treatment, at times cautious, willingness to comply with the dentist, at times with reservation but patiently follows cooperatively

Rating 4 - Definitely positive. Good rapport with the dentist. Interested in the dental procedures, laughing and enjoying the situation.

The Tell-Show-Do method (Addelston 1959) was employed in communicating with the children in vocabulary suited to their ages. Demonstration of the exact procedure to be carried out was conducted. After ensuring proper completion of the forms, Frankl's ratings 1 and 2 were categorized as negative and ratings 3 and 4 as positive. Data was analysed with Epi-info programme.. Frequency tables of variables were generated and cross tabulations were derived where necessary. The Chi square test was employed to determine association between variables.

\section{RESULTS}

The frequency distribution of the mother's past dental experiences is shown in Table 1. Mothers of $40(15.4 \%)$ children had previous positive dental experiences, $25(9.6 \%)$ had negative experiences, while 166(63.8\%) had never visited the dentist. It appears that the children whose mothers had experienced pleasant dental treatment in the past tended to be more cooperative in the early parts of the dental treatment procedures. Thirtyseven $(92.5 \%)$ children whose mothers had 
past pleasant dental experiences reacted positively on entering the operatory as compared to $15(60 \%)$ whose mothers had unpleasant dental experiences This was statistically significant $\left(X^{2}=10.48 ; p=\right.$ 0.000364). Similar findings were demonstrated on seating the child and at the appearance of the operator, although these were not statistically significant.

During examination, 37(92.5\%) children whose mothers enjoyed dental treatment in the past complied while $17(68 \%)$ of children whose mothers had negative experiences, manifested good behaviour. This was statistically significant $\left(X^{2}=11.44 ; p=\right.$ 0.009585) (Table 2). The behaviour of the children at the different phases of treatment is revealed in Table 3. While having prophylaxis done, there was absolute compliance in the children whose mothers had pleasant memories of their dental encounters.

TABLE 1: Frequency Distribution of Mother's Past Dental Experience

\begin{tabular}{lcc}
\hline Mothers Past Dental Experience & $\mathbf{n}$ & $\%$ \\
\hline Pleasant & 40 & 15.4 \\
\hline Indifferent & 29 & 11.2 \\
\hline Unpleasant & 25 & 9.6 \\
\hline No prior exposure & 166 & 63.8 \\
\hline TOTAL & $\mathbf{2 6 0}$ & $\mathbf{1 0 0}$ \\
\hline
\end{tabular}

$\mathrm{n}=$ Number of respondents

TABLE 2: The Effect of Mother's Past Dental Experiences on the Behaviour of Children at the Initial Stages of Treatment.

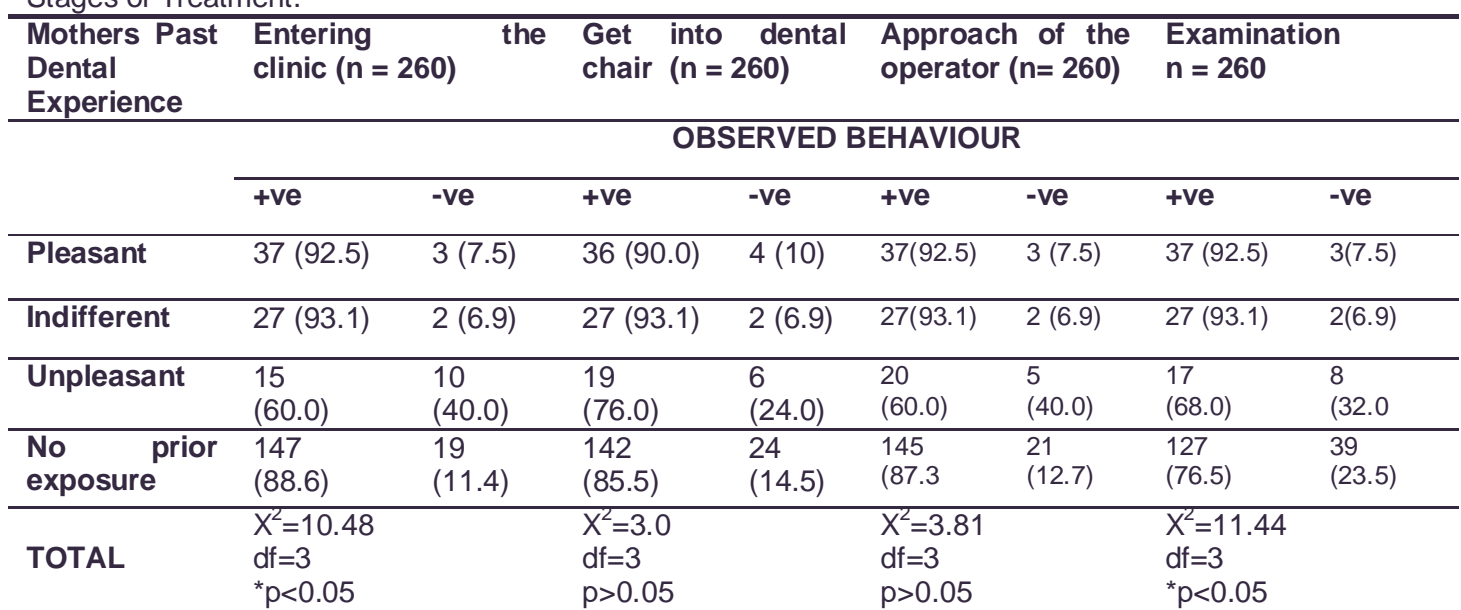

$\mathrm{n}=$ Number of Respondents; +ve= Positive behaviour; -ve= Negative behaviour

( Figures in parentheses are percentages); " statistically significant

TABLE 3: The Effect of Mother's Past Dental Experiences on the Behaviour of Children during the Treatment Phase

\begin{tabular}{|c|c|c|c|c|c|c|c|c|c|c|}
\hline \multirow[t]{3}{*}{$\begin{array}{l}\text { Mother's } \\
\text { Past Dental } \\
\text { Experience }\end{array}$} & \multicolumn{2}{|c|}{$\begin{array}{l}\text { Radiograph } \\
n=24\end{array}$} & \multicolumn{2}{|c|}{$\begin{array}{l}\text { Prophylaxis } \\
\mathrm{n}=98\end{array}$} & \multicolumn{2}{|c|}{$\begin{array}{l}\text { Local } \\
\text { Anesthesia } \\
n=95\end{array}$} & \multicolumn{2}{|c|}{$\begin{array}{l}\text { Restoration } \\
n=28\end{array}$} & \multicolumn{2}{|c|}{$\begin{array}{l}\text { Extraction } \\
n=72\end{array}$} \\
\hline & \multicolumn{10}{|c|}{ OBSERVED BEHAVIOUR } \\
\hline & $+\mathrm{ve}$ & - ve & $+\mathrm{ve}$ & $-\mathrm{ve}$ & $+\mathrm{ve}$ & - ve & $+\mathrm{ve}$ & -ve & $+\mathrm{ve}$ & -ve \\
\hline Pleasant & $\begin{array}{l}4 \\
(100)\end{array}$ & $\begin{array}{l}0 \\
(0)\end{array}$ & $\begin{array}{l}15 \\
(100)\end{array}$ & $\begin{array}{l}0 \\
(0)\end{array}$ & $\begin{array}{l}10 \\
(62.5) \\
\end{array}$ & $\begin{array}{l}6 \\
(37.5) \\
\end{array}$ & $\begin{array}{l}4 \\
(100)\end{array}$ & $\begin{array}{l}0 \\
(0)\end{array}$ & $\begin{array}{l}9 \\
(81.8)\end{array}$ & $\begin{array}{l}2 \\
(18.2)\end{array}$ \\
\hline Indifferent & $\begin{array}{l}6 \\
(100)\end{array}$ & $\begin{array}{l}0 \\
(0)\end{array}$ & $\begin{array}{l}6 \\
(100)\end{array}$ & $\begin{array}{l}0 \\
(0)\end{array}$ & $\begin{array}{l}10 \\
(62.5)\end{array}$ & $\begin{array}{l}6 \\
(37.5)\end{array}$ & $\begin{array}{l}5 \\
(83.5)\end{array}$ & $\begin{array}{l}1 \\
(16.7)\end{array}$ & $\begin{array}{l}7 \\
(63.6)\end{array}$ & $\begin{array}{l}4 \\
(36.4)\end{array}$ \\
\hline Unpleasant & $\begin{array}{l}4 \\
(80.0)\end{array}$ & $\begin{array}{l}1 \\
(20.0)\end{array}$ & $\begin{array}{l}3 \\
(75.0)\end{array}$ & $\begin{array}{l}1 \\
(25.0)\end{array}$ & $\begin{array}{l}3 \\
(33.3)\end{array}$ & $\begin{array}{l}6 \\
(66.7)\end{array}$ & $\begin{array}{l}3 \\
(60.0)\end{array}$ & $\begin{array}{l}2 \\
(40.0)\end{array}$ & $\begin{array}{l}4 \\
(57.1)\end{array}$ & $\begin{array}{l}3 \\
(42.9)\end{array}$ \\
\hline $\begin{array}{l}\text { No Prior } \\
\text { exposure }\end{array}$ & $\begin{array}{l}7 \\
(77.8)\end{array}$ & $\begin{array}{l}2 \\
(22.2)\end{array}$ & $\begin{array}{l}60 \\
(82.2)\end{array}$ & $\begin{array}{l}13 \\
(17.8)\end{array}$ & $\begin{array}{l}24 \\
(44.4)\end{array}$ & $\begin{array}{l}30 \\
(55.6)\end{array}$ & $\begin{array}{l}11 \\
(84.6)\end{array}$ & $\begin{array}{l}2 \\
(15.4)\end{array}$ & $\begin{array}{l}21 \\
(48.8)\end{array}$ & $\begin{array}{l}22 \\
(51.2)\end{array}$ \\
\hline
\end{tabular}

$n=$ Number of Respondents; +ve=Positive behaviour; -ve= Negative behaviour; (figures in parentheses are percentages) 
Of children who had mothers with previous traumatic experiences, only 3(75\%) were cooperative. In the same way, during tooth extraction, $9(81.8 \%)$ of children with positive maternal experiences reacted positively while $4(57.1 \%)$ of their counterparts with negative maternal experiences complied. Behaviour in these latter stages of treatment revealed a tendency of children towards being influenced by the previous dental experiences of their mothers, as there was a general trend towards improved behaviour where the mothers past dental experience had been pleasant. These observations were however not statistically significant.

\section{DISCUSSION}

A child's pattern of behaviour is largely determined by how he becomes conditioned to several elements in his environment. A significant conditioning force has been found to be the childs family (Gershen, 1976)..According to Lencher (1975), misbehaviour may stem from the family unit. One of the ways is by behaviour contagion in which a negative behaviour can be passed on from one family member to the other". He asserts that incorporation of attitudes and behaviour patterns from parents and siblings is as common as contracting measles from family members or friends. Data has revealed that fearful dental patients come from families that have had previous unfavourable dental experiences and in particular where these attitudes are typically expressed (Shoben and Borland 1959,alKhodair et al, 1996, Locker et al, 1999).

Observations from this study have revealed that to a certain extent mothers past dental experiences were related to the behaviour of the child during dental appointments. Children of mothers with past pleasant dental experiences exhibited a tendency to better behaviour than those with traumatic dental experiences. This finding was significant at the initial stages of treatment. On entering the operatory, 92.5\% of children who had mothers with past pleasurable dental experiences reacted positively in comparison to $60 \%$ whose mothers had unpleasant experiences. During examination majority of the children (92.5\%) with positive maternal experiences complied while $68 \%$ of whose mothers had previous traumatic dental experiences exhibited good behaviour. These findings corroborates those of Shaw (1975), Klingberg et al, (1995) and Arnrup (2002). During the operative procedures no statistical association was found. Nevertheless there was a general trend to improved behaviour when mothers past dental experience had been pleasurable.

It was noted however that majority of mothers (63.8\%) in our study had never visited the dentist and as such the influence of the mothers past dental experience in a high percentage of the children could not be determined. This may account for the statistical insignificance recorded during the operative procedures.

The mother is an important figure in the family and usually considered as the cornerstone. Even though everyone in the family can affect the behaviour of a child, the mothers influence is usually the most important as she plays a role in helping the child develop expected behaviour patterns. This is because the mother child relationship is very important in early development and the mother can be a determinant of an anxiety reaction in a child (Muris et al, 2000). Many adults who are afraid of dental treatment often verbalize these dislikes and fears in front of their children and this model may serve as a model on which they base their behaviour (Brand 1976). Children are impressionable and therefore susceptible to imitating models in their environment. Research on the role of parental fearfulness and modeling in children's fear has revealed that children of fearful mothers who often expressed their fears were very fearful themselves (Muris et al, 1996). A mother who bears anxieties as a result of her own previous dental experience can transmit it to her offspring and this may produce a phobia of dental treatment in the child with preconceived notions even before the actual visit (Mathewson et al 1987).

In the light of the findings of this study, the history of dental experiences of the mother is essential and has been found to influence the behaviour of children in south western Nigeria when they attend dental clinics.For this reason, it is pertinent for dentists in this environment and similar ones to enquire about these experiences and where it has been traumatic, it is important that they should educate, counsel and allay fears which may have persisted in such parents for years. This will help reassure the parents as the mothers cooperation will be needed in order to provide children with the best dental care. Parents are valuables resources that can serve as a source of encouragement and motivation for their children (Peretz and Zadik 1998). Furthermore parents especially mothers 
should also be cautioned about the effect of discussing dentistry in the presence of children as they are impressionate and scary stories related to children by adults have been reported over the years as sources of misbehavior in the clinic (Morgan et al, 1980). Mothers should also avoid using the dental visit as a threat to the child.

In some circumstances where the mothers past unpleasant experiences have been found to influence the child behaviour negatively, appropriate behaviour management techniques such as Tell-ShowDo, behaviour shaping, modeling and reinforcement should be instituted in these children in order to bring about improved behaviour during dental appointments. If these fears are not addressed, they do not only disrupt the performance during clinical procedures but they tend to undermine the relationship between the dentist and child patient (Brand, 1999). These fears may continue to adulthood leading to increase frequency of missed and cancelled appointments and patients making only emergency dental visits (Symth 1999, Skaret et al, 2000).

Effective communication is important in development of good patient rapport. The entire dental team should recognize this and see themselves as having a stake in guiding the child throughout the dentist experience. The environment is a critical aspect of communication. A friendly and homely atmosphere, welcoming smile of the receptionist, lovely décor of the room and toys in the waiting area are invaluable in making these children more receptive to oral care.

It also appears that there is a high level of ignorance and unawareness about dental treatment among mothers of children visiting the dental clinic. Almost two thirds (63.7\%) of the parents of the children had never visited the dentist. For this reason it is recommended that the society should be adequately informed concerning oral health education. This information can be disseminated at all levels of government. Public awareness can be created through print media, television and radio programmes. Since there are other variables which may influence the behaviour of children it will be important to investigate these.

\section{REFERENCES}

Addelston H.K. (1959): Child patient training. Fort. Rev. Dent. Soc., 38: 7-9 and 27 -29.
Al- Khodair , I., al Balawi S., al Khamis ,H., and Marks I (1996) Dental phobia among Saudis. Anxiety, 2 (3): 140-4.

Arnrup, K., Berggren , U., Broberg ,A.G., Lundin ,S.A., and Hakeberg,M. (2002): Attitude to dental care among parents of uncooperative vs coopereative child dental patients. Eur J Oral Sci. 110(2): 75-82

Brand A. A. (1976): Some sources of children's fear in the dental situation. J. Dent. Ass. S. Afr , 31: (1) 5-8.

Brand A.A. (1999) .The child dental patient. Part 1. The nature and prevalence of childrens dental fears. South African Dental Journal, 54:(10) 482-7

Dionne, R.A., Gordon, S.M., Mc Cullagh, L. M and Phero J.C. (1998): Assessing the need for anaesthesia and sedation in the general population J. Am. Dent .Assoc., 129(2): 167-73

Finn S.B (1973) Clinical Paedodontics. $4^{\text {th }}$ edition. WB Saunder Co. Philadelphia, London and Toronto

Frankl, S.N., Shiere, F.R., and Fogels, H.R.(1962) Should the parent remain with the child in the dental operatory? J.Dent. Child. 29:150-163.

Gershen J.A (1976) Material Influence on Behaviour Patterns of children in the dental situation. J.Dent child, 43: (1)28-32.

Hawley ,B. P., Mc Corkle, A.D., Whitemann, J. K. and Ostenberg P. V. (1974): The first dental visit for children from low socio-economic families. J. Dent. Child, 41: $376-381$.

Klingberg, G., Berggrien,U., and Noven J.G.(1994): Dental fear in an urban Swedish

population :prevalence and concomitant factors. Community Dental Health, 11:208-214

Klinberg, G., Berggren, U., Carlsson, S. G. and Noren JG (1995): Child dental fear, cause-related factors and clinical effects. Eur J Oral Sci. 103(6): 405-12

Korf S.R (1977). The prevention of child behaviour problems in the dental office .A humanistic approach. J. Prev. Dent. 4:23-29

Lautch, H. (1971). Dental Phobia Brit.J. Psych. 119:151-158

Lenchner, V. (1975): The influence of the family. In Wright GZ. (1987). Child Management in Dentistry. John Wright and Sons. $2^{\text {nd }}$ Edition. $\mathrm{Pg}$ 28

Locker D, Liddell, A., Dempster, L. and Shapiro, D. (1999). Age of Onset of Dental anxiety. J Dent Res. 78(3): 790-6

Mathewson, R. J., Primosch, R. E. and Robertson, D. (1987): Fundaments of Paediatric Dentistry. Quintessence Publishing Co Inc. pg. 137-152

Morgan, P. H., Wright, L. E., Ingersol, B. D. and Seime, P. J. (1980): Childrens perception of the dental experience. J. Dent. Child., 43: (3) 243-245. Muris, P., Steerneman, P., Merckelbach, $\mathrm{H}$ and Meesters, C. (1996). The role of parental fearfulness and modeling in childrens fear. BehavRes Ther, 34(3): 265-8

Muris $\mathbf{P}$, Meesters C, Merckelbach $\mathbf{H}$, Hulsenbeck, P. (2000): Worry in children is related to perceived parental rearing and attachment. Behav Res Ther, 38(5) 487-97 
Peretz, B. and Zadik, D. (1998). Attitude of parents towards their presence in the operatory during dental treatments to their children. J.Clin.Pediatr.Dent.23 (1): 27-30

Semenova, N.D., Kudriavaia, N.V and Zhuruli, N.B (1999): Psychological research in dentistry. Stomatologiia 78(6): 57-64.

Shaw O. Dental anxiety in children. Br. Dent. J 1975; 139: 134-139.

Shoben E. J. and Boland L.(1959): An empirical study of aetiology of dental fears. J. Clin Psychol ; 10: 171-174.

Skaret, E., Raadal, M., Kvale, G. and Berg, E., (2000). Factors related to missed and cancelled dental appointments among adolescents in Norway. Eur J. Oral Sci. 108(3): 175-83.
Sote, E.O. and Sote, G.A.(1985). An assessment of the cooperative behaviour pattern of children at the school of dentistry, Lagos University Teaching Hospital, Idi-Araba . Nig Dent. J. 6 : (1) 41-47

Symth, J.S. (1999). A programme for treatment of severe dental fear. Report of three cases. Australian Dental Journal, 44(4): 275-8.

Wakiaga, J. M., Kaimenyi, J. K. and Kisumbi, B. K. (1996): Reasons underlying failure to seek dental treatment among Nairobi university students. East African Medical Journal. 73(5): 3202.

Winer, GA (1982). Review and analysis of childrens fearful behaviour in dental settings.

Child Development, 54:1111-1133.

Received: December 2003

Accepted in final form: June 2004 